\title{
CONSTRUCTIONS OF "OTHERNESS" AND THE ROLE OF EDUCATION: THE CASE OF ETHIOPIA
}

\author{
SISAy MENGSTIE \\ mengstiesisay7@gmail.com
}

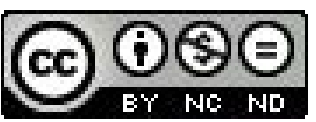

\begin{abstract}
This article attempts to discuss the concept of constructing "otherness", the techniques to be used and the role of educational systems. Ethiopia as a multilingual and multicultural country is the basis of discussion for this concept. Hence, the writer pays due attention to answer the question: How far the Ethiopian educational policy is designed to reflect diversified group interests fairly, if not equally? Therefore, major theoretical assumptions on construction of "otherness" and some practical experiences of the Ethiopian educational systems are thoroughly examined in this paper.
\end{abstract}

Key words: construction, "otherness", education, Ethiopia.

\section{INTRODUCTION}

"Otherness" is the way of defining one's own "self" or one's own "identity" in relation to others. It is mainly a result of social, political, cultural and other kinds of constructions through different approaches. Education as one of the major agents can construct or deconstruct "otherness". Here in Ethiopia, as in many countries in the world, education (it may be traditional, religious, or modern) has played a pivotal role in constructing "otherness".

Indeed, history has prevailed; education has also been serving to construct "otherness" among diversified linguistic, cultural, ethnic, religious, gender, etc. groups for the benefit of the dominant groups. Therefore, in this article the writer tries to explain the concepts of "otherness", its relationship with stereotypes and prejudices and finally analyzes the disadvantages and the possible roles of education in Ethiopia in relation to construction of "otherness".

\section{THE CONCEPT OF "OTHERNESS"}

The term "otherness" simply means a quality of being not alike; being distinct or different from that which is otherwise experienced or known. Most of the time, otherness is interpreted by referring to two or more different groups' distinct features or by referring to special qualities of each group that makes them different or unique in relation to another. This experience of being other can be expressed in many ways. Usually age, ethnicity, sex, physical ability, race, sexual orientation, social-economic class, and other demographic factors are the most common 
factors for an individual or a society to be leveled or identified as being of a certain kind (Gallos, Ramsey 1997, p. 45).

According to Selcen Dogan's explanation, although the sources of otherness are numerous and they are extremely different in their types, it is mainly related with the "terms of identity and difference" (Dogan 2000, p. 16). He further argued that: in the fields of feminism, cultural studies and sociology, "difference" increasingly replaces the concept of "otherness". This explanation leads us to the essential meaning making process of human beings based on their differences. For instance, to talk about male identity, it is first essential to know about "femaleness". Or to judge about the identity or, sometimes, about the qualities of certain ethnic groups they must be compared with other groups. It is mainly this knowledge of difference that helps us to create meanings. Without the knowledge of difference meaning could not exist.

"...there are two general points to note here, first, from many different directions, and within many different disciplines, this question of »difference « and »otherness « has come to play an increasingly significant role. Secondly, »difference« is ambivalent. It can be both, positive or negative. It is necessary for the production of meaning, the formation of language and culture and for social identities - and at the same time, threatens, a site of danger, of negative feelings, of splitting, hostility and aggression towards the »Other «" (Hall 1997, p. 238 in Dogan 2000, p. 17).

Therefore, the central idea of otherness lies just on the divide, like normal and abnormal, insiders and outsiders, and it is generally the issue of "Us" and "Them". This division usually leads to Stereotyping, which is part of the maintenance of social and symbolic order. As illustrated by S. Dogan, stereotype "sets up a symbolic frontier between the normal and the deviant, the normal and the pathological, the acceptable and the unacceptable, what belongs and what does not or is Other, between insiders and outsiders, »Us« and »Them «" (Dogan 2000, p. 18).

\section{POSSIBLE AGENTS AND ASPECTS OF CONSTRUCTING "OTHERNESS"}

As explained, in many ways, otherness is the result of constructions of identities through continuous interactions of human beings. In this case it is more related with constructions of individual and/or groups' identities. Hence, identity can be constructed or reconstructed through social interactions, cultural practices and value exchanges, political setups or decisions, and educational processes.

In addition, there are many agents for the process of constructing otherness. The major agents include: social interactions, education, Media, literature, art (music, drama, theater, and film), folklore, etc. In the process of constructing otherness education plays the dominant role in many ways. Because education has the ability to construct or deconstruct one's own identity at individual and/or group levels.

\section{STEREOTYPES AND "OTHERNESS"}

The concept of stereotype is highly related with that of "othering" and "otherness". Like "otherness" stereotype is dominantly about "Us" and "Them". So examining stereotype helps us to understand how "otherness" can be constructed 
and it is very important to know the very notion of the term. Thus, Stereotype refers to a fixed mental impression of human beings. Or as described by Gordon Allport, stereotype can also be defined as an exaggerated belief associated with a category. Its function is to justify or to rationalize our behavior in relation to that category. This definition implies a discrepancy between an objectively ascertainable reality and a subjective perception of that reality (Van den Berghe 1996, p. 354 in Dogan 2000, p. 9).

\section{CHARACTERISTICS OF STEREOTYPES}

So we can characterize Stereotype as over generalizations of a whole group in to one and the same. It simplifies and ignores social, cultural, and other types of diversities. All comments or group characteristics are presented as if they are universal to the whole group and to each individual member of that group, often as specific group or national characters that are inherent, natural, and therefore unchangeable. These characteristics are very often couched in terms of an implicit moralizing dichotomy, which draws boundaries between "Them" and "Us". But these boundaries are not merely passively descriptive; they incorporate a value judgment of the group that is embedded in the power differential between the various groups within that society. Stereotypes are thus highly emotionally charged (Breger, Hill 1998, p. 11).

"We are told about the world before we see it. We imagine most things before we experience them. And those preconceptions... govern deeply the whole process of perception. They mark out certain objects as familiar or strange, emphasizing the difference, so that the slightly familiar is seen as very familiar, and somewhat strange as sharply alien... they are aroused by small signs... aroused, they flood fresh vision with older images and project into the world what has resurrected in memory" (Dogan 2000, p. 8).

\section{CONSEQUENCES OF STEREOTYPES}

Stereotype naturally does not only mean a negative attitude, a belief, or a prior knowledge of persons towards others. It can be either positively or negatively perceived images of groups or individuals towards "others". But most of the time the stereotyped description of groups is closer to prejudice, a mostly negative attitude. So, one of the dangers of stereotypes is that they are very close to prejudice.

"Even that we do not know enough about a group Giddens says that prejudice refers to opinions and attitudes held by members of one group towards another. A prejudiced person's preconceived views are often based on hearsay rather than on direct evidence, and are resistant to change even in the face of new information" (Giddens, p. 212 in Dogan 2000, p. 9)

Hence, it is not difficult to recognize how stereotypes and/or prejudices are practiced. It is not about their representation of reality. But it is believed that if someone needs to clearly understand how ethnic, gender, racial or any other kinds of representation actually works, the set of representational practices or stereotyping should also be critically examined. According to Hall's explanation, Stereoty- 
ping reduces people to a few, simple and essential characteristics, which are represented as fixed by Nature (Hall 1997, p. 257 in Dogan 2000). Although stereotypes have different identities and characteristics based on their types, the dominant types of stereotypes result from cultural or ethnic differences, linguistic, and racial diversities. Likewise, the major causes for stereotypes here in Ethiopia stems from ethnic diversity. Next we will see how ethnic diversity would be a cause for stereotypes and the disadvantages of negative stereotypes.

\section{ETHNIC STEREOTYPES}

As Roza N. Ismagilova explained it (ethnic stereotypes) prejudices and biases significantly and affects inter-ethnic relations and the ongoing processes of national intelligence (Ismagilova 1986).

Indeed, he once defined Ethnic prejudice as "a negative, unfavorable attitude towards a group or its individual members; it is characterized by stereotyped beliefs; the attitude results from processes within the bearer of the attitude rather than from reality testing of the attributes of the group in question" (Ismagilova 1986, p. 107).

Certain stereotypes are prevalent in respect of specific ethnic groups, and what is really important is that an ethnic stereotype is not a generalized image of the real features inherent to a nationality or race, rather it is a derivative of the respective social situation and historical survivals.

Here, if we take the case of "Gurage" (one of the various ethnic groups in Ethiopia) ethnic group as an example, this group is believed to be, on one side, a people who have the tendency for cooperating or helping each other, as smart minded, successful and very fast in businesses areas. On the other side, they are also considered as "people" who are mischievous and unfaithful in business activities, very passive in politics, etc.

\section{DISADVANTAGES OF ETHNIC STEREOTYPES}

A specific ethnos is often characterized as "aggressive", such preconceived judgment affects human relationship and may lead to a conflict situation if an emotional hostility and general negative attitudes are prevalent in respect of this ethnic group.

Needless to mention, a specific ethnic stereotype is a product of historical development, economic conditions and social structure. However, many sociologists' studies of racism and ethnic prejudices indicate that, the greatest intolerance is characteristic of those social strata that fear economic competition and are uncertain of their tomorrow. This instability causes fears and a continuous quest for potential enemies and competitors. This is one major disadvantage of ethnic stereotyping (Ismagilova 1986, p. 108).

In fact, every human being belongs to a certain people. From infancy a person develops love for his/her own language, culture, traditions or identity in general. $\mathrm{He}$ or she perceives and appreciates the culture and customs of other nationalities against the background of possessed cultural values. "If a desire hereby creeps in to contrast and oppose one's own as alien it gives rise to a disdainful and psycho- 
logically hostile attitude towards other peoples, to problems of inert-ethnic relations, discrimination, etc. resulting in ethnic prejudice" (Ismagilova 1986, p. 108).

This phenomenon is related not only to theories which justify the policy of racial discrimination, but also to the concepts of exclusiveness and original development (Ismagilova 1986, p. 108). "When we look at the field of race and ethnic relations, a »stereotype « is often defined as an overgeneralization about the behavior or other characteristics of members of particular groups. Ethnic and racial stereotypes can be positive or negative, although they are more frequently negative. Even ostensibly positive stereotypes can often imply a negative evaluation. Thus, to say that blacks are musical and have a good sense of rhythm comes close to the more openly negative stereotype that they are childish, and happy-go-lucky" (Dogan 2000, p. 9).

\section{THE POSSIBLE ROLES OF EDUCATION}

As explained in the above sections of this paper, education is one of the most important agents in constructing "otherness". For example, in and through education "otherness" can be constructed or reconstructed in many ways. School environments, social interactions of teachers and students in and out of school, teaching learning processes, student-teacher relationships, the nature and contents of subjects, text books (regarding contents, naming, exemplification, historical and cultural contents or their representations for certain groups), language usage, etc. are important factors in the process of constructing otherness.

Therefore, in multicultural societies like Ethiopia, education is expected to be designed in such a way that all diversity groups have equal attention and treatment in the construction process and the contents or approaches of educational systems should be designed as the right representative of each group. As it has been said by many scholars, in diversified societies, education should not only be structured to sustain the power, history, culture, values, beliefs, worldviews, etc. of dominant groups only. Thus, it is only through multicultural educational approaches that peaceful coexistence can be achieved. That is why Patricia G. Ramsey and Leslie R. Williams puts this idea as one of the major goals of multicultural education.

"Its [multicultural education] primary goal is to design systems of education that are culturally relevant and are inclusive, rather than exclusive, to ensurethat all students have a school possessing the skill for social, academic, political and economic successes to teach students to relate respectively both differences and commonalities; and to recognize, investigate and actively challenge injustice" (Ramsey, Williams 2003, p. 260).

By using education as a tool; Ethnic, racial, gender, and other difference can be treated equally or at least fairly. Through education, some conflicts due to such differences would be resolved, peaceful coexistence and respecting each other among diversified groups would be achieved. Building healthy relationships among diversified groups through education, on the other hand needs a well organized and well planed educational curriculum and appropriate school systems in the context of diversified groups. As Harriett D. Romo suggested, there are many ways of improving relationships of diversified groups other than focusing on academic issues only. 
"Consequently, for schools to focus on academia, they must make efforts to prevent ethnic and racial clashes. Recognizing common values (all students want to feel that they belong) and differential power (some groups »belong « more than others) is essentially for maintaining stability and positive relationships in multiethnic classrooms. Interventions to reduce prejudice and discrimination are also essential" (Romo 2001, p. 17).

Educational approaches that have equal or at least fair consideration for all diversified groups are believed to be basic strategies especially to avoid discrimination, stereotypes or prejudices among group members in and outside the school community.

"Educational approaches expose students and teachers to accurate information about other group similarities and differences. When individuals have accurate information, they are less likely to accept stereotypes and adopt prejudices. As students and educators gain knowledge about other groups and their histories, they become more likely to respect members of those groups and cooperate with them. Drawing attention to the process of discrimination, engaging actively in team building, and consulting continuously with students all help develop a new culture of tolerance and understanding" (Romo 2001, p. 17).

Yet, in the process of construction or reconstruction of "otherness", education does not only refer to the formal type of teaching learning process. Rather, it includes different kinds of approaches and teaching learning processes such as: mass education, cooperative education, and other informal educational systems. As H.D.Romo stated it, sometimes instead of teaching facts about different groups to students, "vicarious experience approaches can be inert group educational programs that use films, plays, biographies, novels, and other methods to present members of all groups in a respectful way" (Romo 2001, p. 17) using these materials is very important for students or any target groups for the lessons to understand and recognize the commonalities of all groups and reduce their tendency to draw sharp boundaries between "Them" and "Us".

Educating people and presenting different groups by using the aforementioned approaches may also have negative consequences that might aggravate or be causes for ethnic conflicts, prejudices, and other kinds of group tensions. For instance, if the presentations of such approaches are poor or misleading, or if the images, histories, cultures, values, etc. of certain groups are wrongly presented (whether it is intentional or not) that might lead to disastrous results.

Because of the above confusing contributions of education, multicultural and multilingual states have been very much concerned in their educational polices to serve all linguistic, cultural, gender, racial, and other groups equally as far as possible. Consequently, such countries have developed their own educational approaches and designed teaching strategies that are suitable for their societies.

Approaches such as assimilation, cultural relativism, multiculturalism, ethnocentrism, particularism etc. are also the results of these controversies and yet they have been applied and tested in educational sectors of different countries. Ethiopia as a multicultural nation has also been applying different approaches in her educational programs since the introduction of modern education in the country. 


\section{EDUCATIONAL POLICIES AND CONSTRUCTION OF "OTHER- NESS" IN ETHIOPIA}

The historical development of Ethiopia's educational policy is mainly related to the introduction of modern education in the country during the first decades of the $20^{\text {th }}$ century. By then, when modern education was introduced, educational policy making was almost a strange phenomenon for Ethiopia Tefera Seyoum properly puts in the right way how modern education was introduced in our country as follows:

"Interestingly enough, it [modern education] was an imported item like the car or the radio, with hardly any input from the society. In fact it was a foreign baggage, with foreign teachers, with foreign language as its medium of instruction, with imported curriculums and text books..." (Seyoum 2006).

In relation to educational policy making, fascist Italy, during its five years stay, was the first in Ethiopia to make an attempt. Let alone the other side of the story, the fascist regime introduced educational policy in Ethiopia for the first time in its history. This policy was proposed in two different ways as: "for Italian type schools and schools for colonial subjects". By the same token, this attempt can also be considered as a pioneer in constructing "otherness" through modern education in Ethiopia.

Although, its aim was to make and create a favorable condition for their divide and rule strategy, this educational policy was characterized by multilingual language policy. It allows some majority languages of the country to be used as a medium of instruction in education. This can also be taken as a historical coincidence to consider cultural diversity or cultural pluralism in the country's educational policy for the first time (Getachew, Derib 2006, p. 45).

Moreover, in the history of the Ethiopian educational policy making process, two major attempts were made almost after 47 years of the first educational policy made by the Italian fascists. During those periods the Ethiopian modern educational system was unable to achieve any significant development in any aspect. Rather, scholars criticized the situation as - limited in its access, unable to treat all societies as equal city urban, male, and class biased of the country, as elitist that was accessible for the few, and they were wasteful in general (Seyoum 2006). Both education policies of Emperor Hailesilase and that of the Derg. The education sector review (ERS) and Evaluative research of the general education system in Ethiopia (ERGESE) respectively were criticized as policies of assimilation that reflected the cultures, values, beliefs, religion of the northern highlands of Ethiopia specifically that of Amhara and Tigray regions. This was primarily aimed at achieving the building of an educational system that would contribute to a strong national identity and to survive a strong unified nation that seems the major goal of the two regimes (Getachew, Derib 2006, p. 45-47).

Be that as it may, the current government of Ethiopia tried to design a multilingual language policy in the education sector. EPRDF at first tried to introduce its "ethnic federalism strategy" by providing equal recognition for different ethnic, 
linguistic or cultural groups in the country. For instance Article 39, 2 in the constitution provides several rights for Nations, Nationalities and peoples as follows:

"Every Nation, Nationality and People in Ethiopia has the right to speak, to write and to develop its own language; to express, to develop and to promote its culture; and to preserve its history" (The Constitution of the Federal Democratic Republic of Ethiopia 1995, p. 96).

This constitution also gave a special emphasis for cultural and linguistic diversity in relation to language choice and language use for different activities. In article 5 sub articles 1 and 3 are the best examples of this:

"1. All Ethiopian languages shall enjoy equal state of recognition

3. Members of the Federation may determine their respective languages".

As a result of such rights in the constitution, regional states have chosen their respective official languages for various purposes. Several languages have the opportunity to be used for official, education, medium of communication, media and other activities in different parts of the country. Following the above rights under the constitution, the 1994.

Ethiopian education and training policy also introduced a new trend in relation to language use in education. Section 3.5.1 of the Education and Training Policy (1994) reads: "Cognizant of the pedagogical advantage to the child in learning in mother tongue and the rights of nationalities to promote the use of their languages, primary education will be given in nationality languages" (Education and Training Policy 1994).

Because of these covert policies and strategies given by the government, different linguistic groups and regional sates started enjoying their languages for educational purposes at different levels. In principle it is important for these groups to design their local or regional education policies to serve as a means of expressing their own cultural, ethnic, social, and historical identities. But the new multilingual education policies of regional states also started to face new forms of challenges by the time of implementation.

For example, language as one of the dominant factors in designing education policies at any level and as a major contributor in the processes of constructing "otherness" is a good example to show the challenges of these new multicultural and multilingual policies in Ethiopia. The statuses of many languages to be used for educational activities were low. The presence of different dialects and language groups in specific areas was also becoming a cause for conflicts and a problem for choice of one language for educational purposes. The lack of skilled manpower, scarcity of teaching materials, and in the ability to produce new books and written documents in most of the minority languages were also some of he challenges to implementation of the policies.

\section{CONCLUDING REMARKS}

It is a widely accepted fact that, education plays a vital role in the overall development of human activities. It has been serving as a source of power in intellectual, social, material, psychological, economic and other areas of development that human beings have been trying to succeed in for a long period of time. However, in this article it is neither possible to mention or beyond its scope to discuss and 
illustrate the possible roles of education in Ethiopia in every aspect. Rather, the writer tried to focus on particular issues in the meaning and process of construction of "otherness", and the possible roles of education in Ethiopia.

Education as one of the major agents for constructing and/or deconstructing "otherness" in diversified societies and has a significant position in the social, historical, cultural, developments, and the past experiences of Ethiopia just as in many other countries, are results of modern and/or traditional educational systems. The remarkable achievements of the past (in different fields), social interactions, traditional ways of life and world views, traditional laws or judicial/legal systems, folklore, folk medicines etc. are highly related to education.

These things have also played significant roles for the well being of the people and to living peacefully within their groups and with other groups and it helps these groups to understand the identity of members of others and to define themselves. This is one important essence of constructing "otherness" in and through education. Nowadays, in the age of globalization, education continues as one of the leading factors in the process of constructing and deconstructing "otherness".

\section{BIBLIOGRAPHY}

Akintunde O. (2001), White racism, white supremacy, white privilege, $\mathcal{E}$ the social construction of race: Moving from modernist to postmodernist multiculturalism, [in:] Schultz F. (ed.), Multicultural Education, McGraw-Hill/Dushkin, Connecticut.

Ayalew E. (ed.) (2006), Proceedings of the conference on Teacher Education for sustainable Development in Ethiopia, Addis Ababa University, Addis Ababa.

Areaya S. (2006), The process of policy formulation and curriculum Soul, speaking from the Heart, Jossey-Bass Publishers, San Francisco.

Education and Training policy (1994), TGE (Transitional Government of Ethiopia), Addis Ababa.

Gallos J.V., Ramsey V.J. (1997), Teaching Diversity: Listing to the soul, speaking from the heart, Jossey-Bass Publishers, San Francisco.

Getachew A., Derib A. (2006), Language policy in Ethiopia, Jimma University Publishers, Jimma.

Ismagilova R.N. (1986), Ethnic Stereotypes and Problems of National Integration in Contemporary Tropical Africa, "Proceedings of the ninth international congress of Ethiopian studies Moscow", Vol. 3.

Negash T. (2006), Education in Ethiopia: From crisis to the brink of collapse, Nordiska Afrikainstitute, Uppsala.

Ramsey P.G., Williams L.R. (2003), Multicultural Education, Routledgefaimer, New York, London.

Romo H.D. (2001), Improving ethnic and racial relations in the schools, [in:] Schultz F. (ed.), Multicultural Education, McGraw-Hill/Dushkin, Connecticut.

Schultz F. (ed.) (2001), Multicultural Education, McGraw-Hill/Dushkin, Connecticut.

Sleeter Ch.E. (1996), Multicultural Education as Social Activism, State University of New York Press, Albany.

Seyoum T. (2006), Educational Policy and Development: The Ethiopian Case, [in:] Ayalew E. (ed.), Proceedings of the conference on Teacher Education for sustainable Development in Ethiopia, Addis Ababa University, Addis Ababa.

Teshome G.W. (1986), Education and society in contemporary Ethiopia, "Proceedings of the ninth international congress of Ethiopian studies Moscow", Vol. 3.

The Constitution of the Federal Democratic Republic of Ethiopia, $19951^{\text {st }}$ year No. 1., Addis Ababa.

Yeo F. (2001), The Barriers of Diversity: Multicultural education and rural schools, [in:] Schultz F. (ed.), Multicultural Education, McGraw-Hill/Dushkin, Connecticut.

\section{NETOGRAPHY}

Dogan S. (2000), Turkey, as "other" and being "othered", http:/ / www.selcendogan.com, retrieved 21.03.2012. 